Motrivivência Ano XXI, No 32/33, P. 389-400 Jun-Dez./2009

\title{
PARTICIPAÇÃO EM LOCAL DE LAZER DE INDIVÍDUOS COM MOBILIDADE REDUZIDA SECUNDÁRIA A LESÃO NEUROLÓGICA
}

\author{
Sarah Souza Pontes' \\ Antonio Lima dos Prazeres² \\ Lucas Lopes ${ }^{3}$
}

\begin{abstract}
Resumo Abstract
O lazer, quando pensado para pessoas com mobilidade reduzida deve considerar suas características

e necessidades, para garantir seus direitos estabelecidos na declaração de direitos humanos de 1999. O objetivo da pesquisa consistiu em investigar a participação em locais de lazer sob a óptica de indivíduos com mobilidade reduzida secundária a lesão neurológica. A metodologia foi o corte transversal realizado em locais especializados em prestar serviço de fisioterapia neurológica. Os dados foram obtidos
\end{abstract}

1 Fisioterapeuta especialista em neurologia e mestranda em Desenvolvimento Humano e Responsabilidade Social. Fundação Visconde de Cairú. Contato: fisioterapia.sarahpontes@gmail.com

2 Fisioterapeuta especialista em neurologia e mestrando em Medicina e Saúde, professor titular da disciplina Fisioterapia em Neurologia II. Faculdade Social da Bahia. Contato: antonioprazeres@ yahoo.com.br

3 Fisioterapeuta especialista em neurologia. Universidade da Bahia. Contato: fisioterapia.sarahpontes@gmail.com 
através da aplicação de questionário, categorizados, apresentados em percentuais e analisados à luz de referenciais teóricos atuais. Estes demonstraram que os indivíduos com mobilidade reduzida pouco freqüentam

locais de lazer e quando esta prática ocorre os locais mais visitados são aqueles que oferecem diversão gratuita.

Palavras-chave: Lazer; Lesão neurológica; Mobilidade reduzida. application, categorized, presented in percentages and analyzed in accordance with the current references. These results had evidenced that the individuals with reduced mobility frequent the leisure places little and when this practical exists the visited places more is those that offer free entertainment

Keywords: Leisure; Neurological injury; Reduced mobility.

\section{Introdução}

O termo "deficiência" é determinado por representações sócio-culturais de cada comunidade em diferentes épocas históricas e pelo nível de desenvolvimento científico, político, ético e econômico dessa sociedade. Os designados "deficientes" sempre foram vistos com rejeição, preconceito e exclusão social. (SILVA, 2006).

Segundo o Decreto Federal $n^{0}$ 914/93, o indivíduo com deficiência é aquele "que apresenta, em caráter permanente, perdas, anormalidades, anomalia de sua estrutura função psicológica, fisiológica ou anatômica, que gerem incapacidade para o desempenho de atividades, dentro do padrão considerado normal para o ser humano".

Fatores históricos retratam o preconceito como as crenças antigas

associavam a luz a fatos iluminados e situações favoráveis, já a ausência da luz, as trevas, tudo que era mal e que houvesse algo a temer. Nas passagens históricas os deficientes foram vistos de diferentes formas, conforme a época inserida, hábitos, costumes e crendices. (SILVA, 2006).

Em épocas remotas se dirigiam aos deficientes como incapazes, indivíduos nos quais não poderiam ser dotados de nenhuma habilidade. Desta forma, eram sempre discriminados e excluídos do ambiente social, seja qual fosse à faixa etária e classe social. (OLIVEIRA, 2004).

A modificação do quadro de menosprezo em que os deficientes foram submetidos durante épocas teve início no mercantilismo, capitalismo e sistema 
feudal devido a descobertas na área médica. A questão da acessibilidade é um fator estrutural de desenvolvimento do país, já que deve ser atribuído a todos de maneira igual o direito de ir e vir, de ter acesso à informação e à comunicação, são elementos dos direitos humanos e da cidadania. Se torna necessário desta forma adequar o ambiente coletivo ás necessidades apresentadas pela população, não esquecer que uma parcela desta necessitam de soluções especiais para Ihes garantir autonomia e segurança. (CONSELHO NACIONAL DOS DIREITOS DA PESSOA PORTADORA DE DEFICIÊNCIA, 2006).

Muitos consideram que a palavra "deficiente" tem um significado muito forte, carregado de valores e supõe que a pessoa deficiente não é capaz; e, sendo assim, então é preguiçosa, incompetente e sem inteligência. A ênfase recai no que falta, na limitação, no "defeito", gerando sentimento de desprezo, indiferença, chacota, piedade ou pena. (MINISTÉRIO DA EDUCAÇÃO, 2000, p.1).

"O desenho universal surgiu como conceito de utilizar formas de transposição de obstá- culos ou barreiras que atendam a todas as pessoas com possibilidade de locomoção não específica". (NOGUEIRA, 2007).

O termo inclusão tem sua origem da palavra integração, mas não seria o mais adequado, pois inclusão não é somente um fator de inserir alguém em um grupo e sim, acolher de forma importante e traduzir este elemento como parte da sociedade. (CRUZ; BARRETO 2003).

Os indivíduos com deficiência ainda são excluídos da sociedade, mas não de maneira evidente e sim devido às barreiras arquitetônicas normalmente encontradas, interferindo no direito de livre acesso e inclusão social principalmente no lazer. A definição de lazer é dita como o conjunto de ações escolhidas pelo sujeito para diversão, recreação e entretenimento, num processo pessoal de desenvolvimento. (ALMEIDA; GUTIERREZ, 2002).

As cidades, edifícios, logradouros públicos e meios de transporte foram e continuam sendo projetados para os cidadãos fisicamente perfeitos, sem a preocupação de integrar e proporcionar facilidades àquela parcela da população que 
apresenta deficiência, física ou visual. (MELO, 1991, p.131).

Estudos nos anos 80 indicam que o lazer e a recreação são fatores importantes no processo de reabilitação e que pessoas bem sucedidas no trabalho tinham antes desenvolvido habilidades de lazer. Estes estudos parecem concluir que a prática do lazer de variados tipos pode melhorar o desempenho numa ampla gama de áreas, tais como a saúde, a resistência física, a motivação e a auto-imagem. (CRUZ; BARRETO, 2002).

Desta forma é de grande valia analisar a participação em locais de lazer de indivíduos em condição de "se movimentar com dificuldade e insegurança, usando ou não aparelhos ortopédicos ou próteses, incluindo-se idosos", o que é caracterizado como mobilidade reduzida segundo a ABNT NBR 10984-3:1996 (1998). Uma vez que se torna indispensável à integração social desta população e este fator exerce influência na reabilitação.

\section{Material e métodos}

O estudo se trata de um corte transversal que foi realizado em locais especializados em prestar serviço de fisioterapia neurológica, tais como: Instituto Bahiano de Reabilitação (IBR), Hospital Santo Antônio e um grupo de reabilitação neurológica domiciliar, no período de junho e julho de 2008. A amostra foi selecionada por conveniência e teve como critérios de inclusão indivíduos com mobilidade reduzida decorrente de lesão neurológica, com faixa etária acima de 18 anos e com critério de exclusão os indivíduos com déficit cognitivo, não podendo responder o questionário.

Foi aplicado à amostra selecionada um questionário semiestruturado previamente elaborado pelos autores. O questionário semi-estruturado foi composto de sete perguntas a respeito dos dados pessoais do participante tais como: local da aplicação que realizava a reabilitação, patologia de base, uso órtese, idade, sexo, raça e estado civil, questões estas subjetivas, porém com respostas breves que se referem a óptica destes em relação a locais de lazer em Salvador-BA. Antes do momento de aplicação dos questionários foi realizado um treinamento dos profissionais que aplicaram estes e posteriormente foi feito um estudo o piloto. 
Ano XXI, n 32/33, junho e dezembro/2009

Todos participantes foram informados dos objetivos desta pesquisa e assinaram o termo de consentimento livre e esclarecido, garantindo os aspectos éticos previstos na portaria 196/96 do Conselho Nacional de Saúde do Ministério da Saúde. Esse estudo foi submetido no comitê de ética do Hospital Santo Antônio e no Instituto Bahiano de Reabilitação (IBR), a fim de seguir o tramite normal para a pesquisa. O termo de consentimento constava os objetivos e a observação que a pesquisa é sem fins lucrativos, onde foi exposta a importância da participação por ser de grande valia para o desempenho profissional e a reabilitação neurológica com a finalidade de uma participação efetiva neste processo.

As respostas obtidas após a aplicação dos questionários foram categorizadas da seguinte forma: relacionadas à ausência ou pouca adaptação do espaço físico foram descritas como acessibilidade deficitária, quando relatavam a carência de uma companhia foi agrupado em ausência de acompanhante, discurso relatando gastos ou pouco dinheiro foram agrupados em problemas de ordem financeira, a dificuldade de chegar até o local por conta de ausência ou pouco transporte acessível foram caracterizados como carência de transporte adaptado, seguido de impedimento devido à religião, gostar ou não do local e por fim alguns expressavam temer atos de violência em locais públicos, os quais foram categorizados respectivamente como: religião não permite, simpatizar com o local e teme a segurança deste. Em seguida para a observação dos resultados foi feita uma análise descritiva, através dos cálculos de percentagem realizados no Excel 2003.

\section{Resultados e discussão}

O estudo foi composto por uma amostra de 50 pacientes com mobilidade reduzida devido à lesão neurológica. Deste tiveram como patologia de base mais representativa Doença Vascular Encefálica com $70 \%$ (35 pacientes), o que se aproxima da literatura como citado por Ryerson (2004) onde refere que a ocorrência de Doença Vascular Encefálica é a maior causa de incapacidade neurológica, com dois em cada mil indivíduos (Tabela1). 
Tabela 1: Patologia de base e ocorrência

Salvador-BA, junho/julho, 2008.

\begin{tabular}{|c|c|}
\hline Patologia & Ocorrência (\%) \\
\hline Doença Vascular Encefálica & $70 \%$ \\
Trauma Raqui-medular & $10 \%$ \\
HTLVI & $8 \%$ \\
Trauma crânio encefálico & $2 \%$ \\
Poliomielite & $2 \%$ \\
Mielite & $2 \%$ \\
Parkinson & $2 \%$ \\
Esclerose Múltipla & $2 \%$ \\
Esclerose Lateral Miotrófica & $2 \%$ \\
\hline Total & $100 \%$ \\
\hline
\end{tabular}

Fonte: Pesquisa de Campo

Em seguida foram questionados aspectos relacionados à participação em locais de lazer, como: cinema e teatros, praças, praias e igrejas, a freqüência ou não nestes locais e no caso da resposta que não era freqüentado o que impedia.

Pode se observar que locais tais como praia, praça e igreja que são locais que a presença é gratuita representam maior percentagem de freqüentadores, ao contrário de cinemas e teatros. (Tabela 2)

Tabela 2: Freqüência em locais de lazer.

Salvador-BA, junho/julho, 2008.

\begin{tabular}{|c|l|l|l|l|}
\hline $\begin{array}{c}\text { Locais de } \\
\text { Lazer }\end{array}$ & $\begin{array}{c}\text { Cinema e } \\
\text { Teatro }\end{array}$ & Praia & Praça & Igreja \\
\hline Freqüenta & $14 \%$ & $28 \%$ & $32 \%$ & $48 \%$ \\
\hline $\begin{array}{c}\text { Não } \\
\text { freqüenta }\end{array}$ & $86 \%$ & $72 \%$ & $68 \%$ & $52 \%$ \\
\hline Total & $100 \%$ & $100 \%$ & $100 \%$ & $100 \%$ \\
\hline
\end{tabular}

Fonte: Pesquisa de Campo 
Ano XXI, n 32/33, junho e dezembro/2009

O fato de a igreja ser o local de lazer mais freqüentado pode estar relacionado há crença que esta população já tem ou busca após uma doença. Alguns estudos sugerem que a doença pode mobilizar a procura de ajuda pela religião por causa da difusão que existe da cura religiosa no Brasil. (REDKO, 1997). Quando questionado em relação às praias foi mencionado por alguns participantes que a religião não permitia tal prática.

Segundo Menicucci 2006, a constituição Brasileira, no seu artigo sexto, define o lazer como um dos direitos sociais junto a outros direitos, como educação, a saúde o trabalho, a moradia, a segurança, a previdência social. O poder público incentivará o lazer, como forma de promoção social. No entanto os resultados apresentados vão de encontro a que preconiza a lei.

Ribeiro et al. 2007 um estudo descritivo foram verificados locais de lazer mais freqüentados em Salvador: teatros, cinemas, parques e praias. Foram avaliados, por meio de uma ficha de avaliação composta de 14 itens de acordo com a Associação Brasileira de Normas Técnicas (ABNT, 2004)- pela norma NBR 9050/94 de Acessibilidade a Edificação, Mobiliário, Espaços e Equipamentos Urbanos. Através da análise dos resultados obtidos nesse estudo, permite-se concluir que os ambientes de lazer avaliados na Cidade de Salvador, apresentam oportunidades de melhoria na maioria dos itens avaliados com relação à $A B N T$.

Este estudo foi muito importante, pois avaliou com base nos aspectos abordados na ABNT, onde observou à dificuldade encontrada pelos indivíduos com mobilidade reduzida nos ambientes destinados ao lazer em Salvado-BA. Desta forma este corrobora com os resultados verificados no presente estudo, porém o que difere é a perspectiva abordada uma vez que Ribeiro et al 2007 tem a abordagem com foco no ambiente e já o presente estudo a óptica do indivíduo. Desta maneira é possível verificar aspetos interessantes, pois o que seria esperado é que os locais mais adaptados como encontrado em Ribeito et al. 2007 fossem os mais freqüentados pelos pacientes, mas não foi isso o encontrado no presente estudo. neste foi observado que seriam os mais adaptados foram os menos freqüentados. O que pode estar relacionado com os recursos financeiros que esta amostra estudada carece.

Foi questionado aos indivíduos o motivo pelo qual não freqüentavam locais de lazer e aos que freqüentavam se achavam adaptados para a população que carece de auxílios para sua mobilidade (Tabela 3). 
Tabela 3: Participação em locais de lazer sob a óptica de indivíduos com mobilidade reduzida secundária a lesão neurológica. Salvador-BA, junho/julho, 2008.

\begin{tabular}{|c|c|c|c|c|}
\hline $\begin{array}{c}\text { Locais de } \\
\text { lazer }\end{array}$ & $\begin{array}{c}\text { Cinema e } \\
\text { Teatro }\end{array}$ & Praia & Praça & Igreja \\
\hline $\begin{array}{c}\text { Acessibilidade } \\
\text { deficitária }\end{array}$ & $18,60 \%$ & $47,22 \%$ & $38,24 \%$ & $38,46 \%$ \\
\hline $\begin{array}{c}\text { Ausência de } \\
\text { acompanhante }\end{array}$ & $11,63 \%$ & $8,33 \%$ & $8,82 \%$ & $7,69 \%$ \\
\hline $\begin{array}{c}\text { Problemas de } \\
\text { ordem financeira }\end{array}$ & $13,95 \%$ & $2,78 \%$ & $2,94 \%$ & $0 \%$ \\
\hline $\begin{array}{c}\text { Carência de } \\
\text { transporte } \\
\text { adaptado }\end{array}$ & $32,56 \%$ & $27,78 \%$ & $32,35 \%$ & $34,62 \%$ \\
\hline $\begin{array}{c}\text { Não simpatizar } \\
\text { com o local }\end{array}$ & $20,93 \%$ & $0 \%$ & $0 \%$ & $11,54 \%$ \\
\hline $\begin{array}{l}\text { Religião não } \\
\text { permite }\end{array}$ & $2,33 \%$ & $0 \%$ & $0 \%$ & $0 \%$ \\
\hline $\begin{array}{c}\text { Motivação } \\
\text { reduzida após } \\
\text { patologia }\end{array}$ & $0 \%$ & $13,89 \%$ & $14,71 \%$ & $7,69 \%$ \\
\hline $\begin{array}{c}\text { Teme a } \\
\text { segurança do } \\
\text { local }\end{array}$ & $0 \%$ & $0 \%$ & $2,94 \%$ & $0 \%$ \\
\hline Total & $100 \%$ & $100 \%$ & $100 \%$ & $100 \%$ \\
\hline
\end{tabular}

Fonte: Pesquisa de Campo realizada em junho/ julho de 2008.

É possível verificar que os cidade de Salvador são: adaptação aspectos que mais interferem em esses deficitária, ausência de acompanhanindivíduos, com mobilidade reduzida, te, problemas de ordem financeira e não freqüentarem locais de lazer na carência de transporte adequado. 
Ano XXI, n 32/33, junho e dezembro/2009

" O transporte não é apenas utilizado para o deslocamento e para ao trabalho, mas ao lazer, às atividades de tratamento médico, dentre outros, a garantia da autonomia e independência, dessa forma a liberdade de ir e vir ao qualquer lugar que se deseje e a qualquer hora.". (LIMA; V, ARRUDA; F, GUERRA; K, 2006, p. 03).

O que pode ser verificado é que as práticas sócio-educativas e as leis que as apóiam não têm si expressado nos resultados coletados, principalmente no que diz respeito aos discursos dos indivíduos com mobilidade reduzida.

A prática do lazer colabora e pode ser utilizado como um auxiliar na terapia dos indivíduos com mobilidade reduzida tanto na motivação quanto a interação com o meio através de vários estímulos e experiências. É sabido que o lazer faz parte das necessidades individuais e sociais participando na motivação desses indivíduos. (RIBEIRO, 2003) essa motivação e experiência de atividades passadas atuam de forma importante na neuroplasticidade e no controle motor favorecendo a recuperação desses indivíduos. (UMPHERD, 2004). Logo é indispensável que profissionais da área de reabilitação neurológica estejam cientes, engajados e atualizados sempre em relação a estes fatores.

\section{Conclusão}

Durante a discussão dos dados foi possível observar a carência de estudos nesta área de pesquisa. Com base nos resultados pode-se observar que aspectos como: adaptação inadequada, ausência de acompanhante, problemas de ordem financeira e a infraestrutura deficitária de transportes são diretamente relacionado com a participação em locais de lazer sob a óptica de indivíduos com mobilidade reduzida secundária a lesão neurológica. Além disso, é possível observar que ambientes como praia, praça e igreja que são locais que a presença é gratuita representam maior percentagem de freqüentadores, ao contrário de cinemas e teatros. o que sugere a grande influência do poder aquisitivo na participação desses pacientes em alguns locais de lazer. Isso é reforçado quando observado que os locais mais adaptados na visão dos pacientes não eram os mais freqüentados.

Os dados obtidos neste estudo possibilita a reflexão de políticas para auxiliar a adaptação de locais não pagos e implementar outras formas de estímulo ao acesso de locais pagos como acesso gratuito 
ou com desconto para deficientes físicos, a fim de contemplar o que a constituição brasileira fala.É notável a necessidade de novos estudos em relação a participação em locais de lazer neste âmbito.

\section{REFERÊNCIAS}

ABNT-Associação Brasileira de Normas Técnicas. Projeto NBR 10984-3:1996. Válida a partir de 29.01.1998

Acesso Brasil. Engenheiro estimula o conhecimento e a aplicação das Normas de Acessibilidade. Disponível em: http://www. acessobrasil.org.br/index. php? itemid $=847$, Acesso em 15 de outubro de 2007.

Adequação de Ambientes. Disponível em: http://www. adfego.com.br. Acessado em 15 de outubro de 2007.

Associação Brasileira de Normas e Técnicas - ABNT NBR 9050. Acessibilidade a Edificações, Mobiliários, Espaços e Equipamentos Urbanos. $2^{\mathrm{a}} \mathrm{ed}$. 2004. Disponível em: http:// www.mg.gov.br/sedh/ct/corde/ dpdh/sicorde/principal/asp. Acesso em 12 de outubro de 2007.

DUMAZEDIER, J. Lazer e cultura popular. São Paulo, Perspectiva, 1973
FARIAS, N.; BUCHALLA, C.M. A classificação internacional de funcionalidade e saúde da Organização Mundial da Saúde: Conceitos, usos e perspectivas. Revista Brasileira de Epidemiologia, São Paulo, vol. 8, n². 2005.

LIMA, N. M. Avanços e Conquistas na Área da Acessibilidade no Brasil. . Ia Conferência Nacional dos Direitos da Pessoa com Deficiência: "Acessibilidade: Você Também tem Compromisso." Caderno de Textos. p. 85-87. Brasília, 12 a 15 de Maio de 2006.

LIMA, N. M. A Legislação e a Política Pública de Inclusão da Pessoa Portadora de Deficiência. I ${ }^{\mathrm{a}}$ Conferência Nacional dos Direitos da Pessoa com Deficiência: "Acessibilidade: Você Também tem Compromisso." Caderno de Textos. p. 12-14. Brasília, 12 a 15 de Maio de 2006.

LIMA, V; ARRUDA, F, GUERRA, K. A Temática da Acessibilidade ás Pessoas com Deficiência no Sistema de Transporte Público Urbano de Fortaleza Empresa de Trânsito e Transporte Urbano S/A - ETTUSA

MENICUCCI, E; MANZINE,E.J. Avaliação de Acessibilidade em Escolas do Ensino Fundamental: descrição da metodologia para elaboração de um protocolo. I $^{\mathrm{a}}$ 
Ano XXI, n 32/33, junho e dezembro/2009

Conferência Nacional dos Direitos da Pessoa com Deficiência: "Acessibilidade: Você Também tem Compromisso." Caderno de Textos. p. 82-84. Brasília, 12 a 15 de Maio de 2006.

MARCELINO, N. C. Lazer e educação. Campinas, São Paulo, Papirus, 1987.

MAZZONI, A. A.; ET AL. Aspectos que interferem na construção da acessibilidade em bibliotecas universitárias. Ci. Inf, 2001 Mai/ ago, 3(2): 29-34.

- Estudos do Lazer uma introdução. Nelson Carvalho Marcellino Terceira edição ampliada. Auditora Autores associados.Campinas - SP. 2002 MAZZOTTA, M.J.S. Acessibilidade e a Indignação por sua Falta. I ${ }^{a}$ Conferência Nacional dos Direitos da Pessoa com Deficiência: "Acessibilidade: Você Também tem Compromisso." Caderno de Textos. p. 30-32. Brasília, 12 a 15 de Maio de 2006.

MENDONÇA, J.M.B. Direitos

Humanos Cidadania e Acessibilidade. I ${ }^{a}$ Conferência Nacional dos Direitos da Pessoa com Deficiência: "Acessibilidade: Você Também tem Compromisso." Caderno de Textos. p. 110-111. Brasília, 12 a 15 de Maio de 2006.

MENDONÇA, K.M.P.P., GUERRA,

R.O. Desenvolvimento e validação de um instrumento de medida da satisfação do paciente com a Fisioterapia. São Carlos: Revista Brasileira de Fisioterapia, v.11, n.5, p.369376, set./out. 2007.

NOGUEIRA, C. O Fisioterapeuta e a Acessibilidade das Pessoas com Deficiência Física. Cíntia Maria Persona Nogueira. São Paulo, 2007 (Dissertação-Universidade Presbiteriana Mackenzie).

OLIVEIRA, R.A. O sujeito e o corpo perante incapacidade física. Revista Portuguesa de Psicossomática, Porto, v.6, p.6367, 2004.

(OMS) Organização Mundial da Saúde, CIF: Classificação Internacional de Funcionalidade, Incapacidade e Saúde. [ Centro Colaborador da Organização Mundial da Saúde para a Família de Classificações Internacionais, org.; Coordenação da Tradução Cássia Maria Buchalla]. São Paulo: Editora da Universidade de São Paulo-EDUSP; 2003.

RIBEIRO, N.M.S. et al. Análise do ambiente de lazer para portadores de deficiência física com alteração na locomoção, na cidade de Salvador. Diálogos Possíveis, Salvador, ano $6, \mathrm{n}^{\circ}$ 1p.235-242, 2007.

RIBEIRO, R. V. A motivação como ferramenta gerencial da mudança. Revista F A E B U 
S I N E S S, [S.L.], n.6, ago, 2003. Acesso em: 11 de abr de 2009. Disponível em: http:// www.fae.edu/publicacoes/pdf/ revista_fae_business/n6/gestao_ motivacao.pdf.

REDKO, C.P. Alguns idiomas religiosos de aflição no Brasil. Psychiatry On-line. Brasil, novembro, 2007. Acesso em: 11 de abr de 2009. Disponível em: http://www.polbr.med.br/ arquivo/relig.htm.

SILVA, L.M. O estranhamento causado pela deficiência: preconceito e experiência. Revista Brasileira de Educação, Rio de Janeiro, v.11, p.424-434, 2006.

UMPHERD, D.et.al. Intervenção para incapacidades neurológicas. In: UMPHRED, D. Reabilitação neurológica. 4. ed. São Paulo: Manole, 2004. cap.4, p. 59-78.

Recebido: Março/2010 Aprovado: Agosto/2010 